\title{
BUSINESS INTELLIGENCE AND ANALYTICS - CONTEMPORARY SYSTEM MODEL
}

\author{
S. Klisarova-Belcheva*, G. Ilieva, T. Yankova \\ Department Management and Quantitative Methods in Economics, Faculty of Economics and \\ Social Sciences, University of Plovdiv Paisii Hilendarski, Plovdiv, Bulgaria
}

\begin{abstract}
PURPOSE: This paper aims to analyze and evaluate the current state of business intelligence systems (BIS) market and outline the main trends in BI technologies development.

METHODS: The main research methods employed are studying BIS characteristics, analysis of market dynamics and the strengths and weaknesses of market participants, which is integrated in drawing conclusions regarding trends in BIS products development and their market, modeling and synthesis in developing innovative BIS architecture.

RESULTS: The trends in BIS products development and their market are outlined, and based on them, a new model of modern BIS architecture is proposed.

CONCLUSION: There is positive dynamics on the BIS market and in 2016 several shifts occurred among vendors, including the emergence of new ones. Users' preferences continue evolving and smart data discovery is sought after at an increasing rate, for example in processing native language queries. A rising number of vendors offer BIS as a service with data being stored in the cloud or on-premise.
\end{abstract}

Key words: data science, advanced analytics, business intelligence framework

\section{INTRODUCTION}

Business intelligence systems (BIS) have been among the most rapidly advancing software products in recent years. Modern companies have always needed such software, but it was in the 10 s of the XXI century that it became widely accessible and virtually indispensable as a convenient means of optimizing costs and increasing revenue. BIS enable companies to constantly monitor key indicators of their productivity, plan and manage company resources properly and cater to their customers' needs as best as they could. Business intelligence is instrumental in making decisions on all managerial levels and it leads to increased operating efficiency thereby giving companies an edge in demanding and challenging market conditions. These advantages bolster the statement that BI market is developing and will continue doing so at a fast pace in the coming years.

According to (1), business intelligence means "knowledge gained through the access and

\footnotetext{
*Correspondence to: $S$. Klisarova-Belcheva, Department Management and Quantitative Methods in Economics, Faculty of Economics and Social Sciences, University of Plovdiv Paisii Hilendarski, Plovdiv, Bulgaria e-mail: stanislava.belcheva@gmail.com
}

analysis of business information. Business intelligence tools and technologies include query and reporting, OLAP (online analytical processing), data mining and advanced analytics, end-user tools for ad hoc query and analysis, and dashboards for performance monitoring."

According to other authors, (2-6), BI is neither a product, nor a system. It is an architecture and a collection of integrated operational applications, applications for analysis and database, which provide a company with simpler ways of using its own information. BI applications aiding decision-making facilitate a number of activities such as multidimensional analysis, clickstream data analysis, data mining, etc.

Mobility, collaborative work, working in the cloud, visual discovery, social analysis and forecasting capabilities are but few of BI innovations from recent years. Changes in the field of BI are so revolutionary, that they can be likened to a BI Renaissance (7).

The purpose of this work is analyzing and evaluating current state of BIS market and outlining significant trends in BI technologies development for the last five years. 


\section{MATERIALS AND METHODS}

This paper summarizes the results of a research study of BIS market for which data from annual reports from leading research and advisory firms such as Gartner, Dresner Advisory Services, and IDC, have been gathered and processed. Base functionalities of modern BI applications for company productivity management and decision making are analyzed. On the basis of BI market trends, a new architectural model for a modern BIS is proposed. This model reflects discovered patterns and could be used as a stepping stone for forecasting future market shifts.

Methodology employed in this paper includes:

- content analysis and secondary analysis for researching the BI market as a dynamic collection of participants (suppliers and buyers), BI instruments and their characteristics;

- comparative analysis - for determining the similarities and differences in research conducted by the mentioned research and advisory companies;

- for statistical analysis and objectivization of obtained results, the following methods were used: tabular, graphical and
KLISAROVA-BELCHEVA S., et al. descriptive analysis, as well as dispersion analysis in MS Excel 2016;

- regression analysis, moving averages, and exponential smoothing - for forecasting trends in sales volume (in monetary terms) and market share of suppliers via Analysis ToolPak in MS Excel 2016;

- generalization of empirical data and uncovering relationships between market participants;

- modeling and synthesis in developing a modern BIS architecture.

\section{RESULTS}

The main results of this work are the following: trends in $\mathrm{BI}$ products development and their market are outline and based on these trends, a new architecture of a modern BIS is proposed.

\section{Companies leading the BIS market}

A competitive environment is characterized by being dominated by large and traditional BI suppliers. The leader's quadrant is again occupied by Microsoft, Qlik and Tableau as it has been for some years now, and these companies are developing fast (having 10\%, $11 \%$ and $58 \%$ sales growths in monetary terms in 2015, respectively) (Figure 1) (8-9).

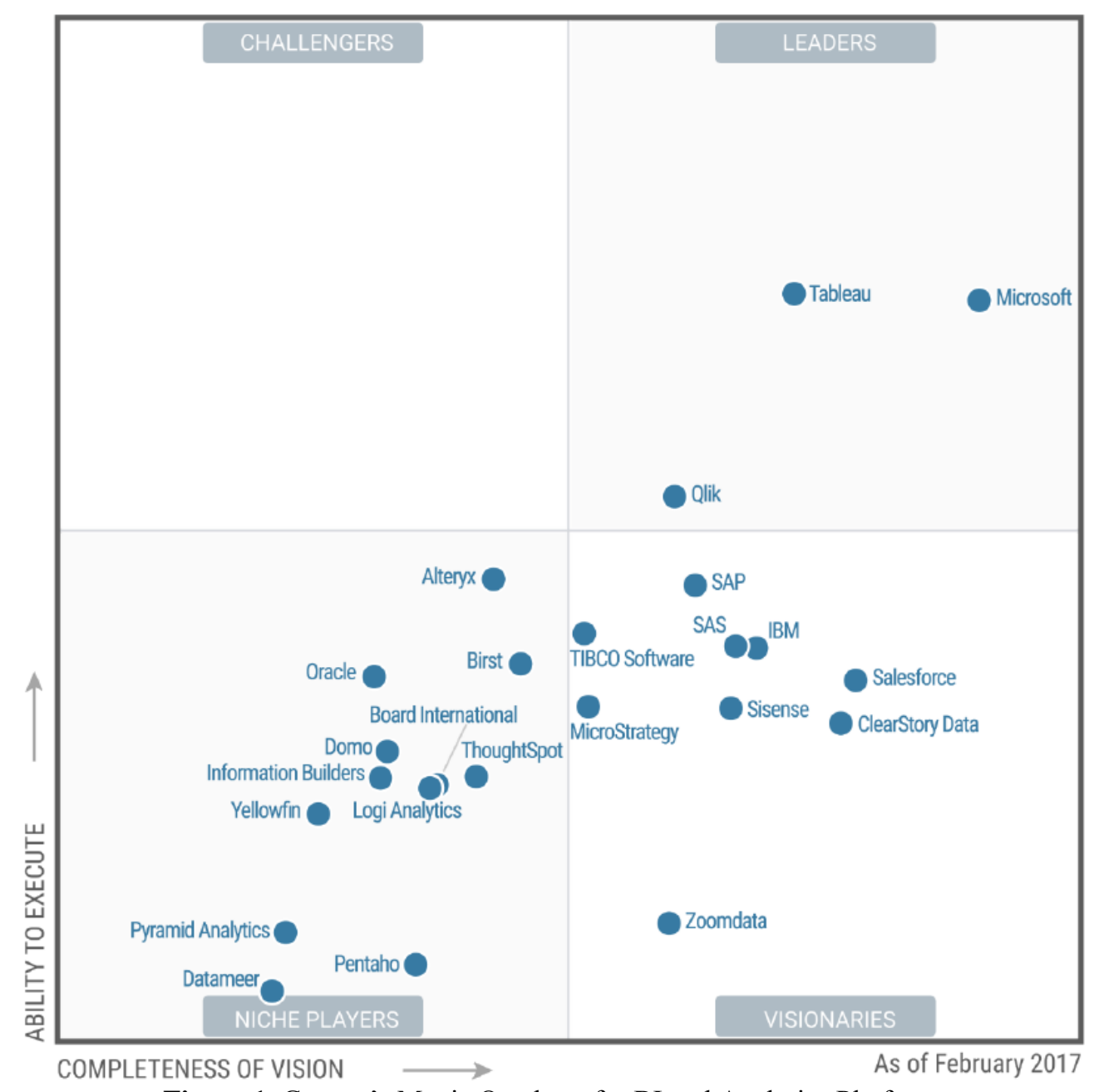

Figure 1. Gartner's Magic Quadrant for BI and Analytics Platforms

(Source: Gartner, 2017) 
In order to trace the latest changes in behavior of the main participants in the BI market, we will use data from a research conducted by Capterra (10). Table 1 shows that the list of top $10 \mathrm{BI}$ products from the last two years contains not only products by business software companies, but also such by companies that create only BIS. These products were ranked according to Capterra Market Score - an

assessment that has been formed using the Simple Additive Weighting method taking into account total number of customers, total number of users and total number of social
KLISAROVA-BELCHEVA S., et al. networks followers. Analyzing the ranking, shows that Tableau demonstrates the largest improvement - it moved from sixth place in 2016 to first place in 2017. In 2016, the leader's number of customers and users has increased dramatically, with about $56 \%$ and $598 \%$, respectively, while the average growths in consumers and users were about $10 \%$ and $30 \%$, respectively. The change in the number of social network followers on Facebook, LinkedIn and Twitter was also significant. This customer base expansion is an indicator of the increased importance of BIS for modern companies and their employees.

Table 1. The ten most popular BI products in the world in 2016 and 2017.

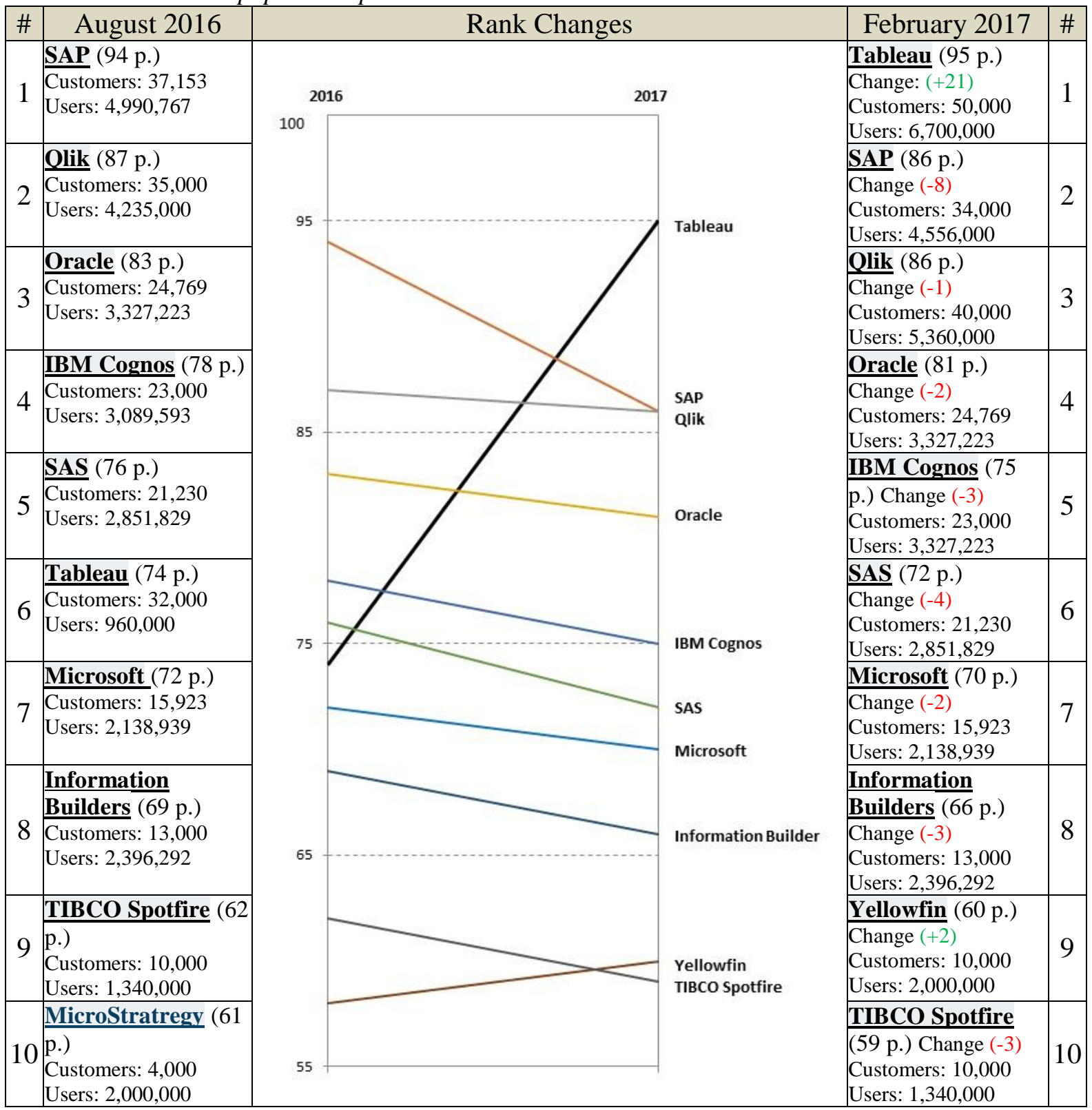

\section{BIS market - present and future}

Grobal sales from business intelligence and analytical software are expected to reach $\$ 18.3$ billion in 2017, which is an increase of $7.3 \%$ compared to 2016. It is expected that by the end of 2020, the total market will be $\$ 22.8$ billion (8).

Business intelligence software sales grow by $3 \%$ in 2015 to a total volume of about $\$ 14$ billion. After compensating for exchange rate 
effects, the market has increased by $11.7 \%$. Among the market's three major segments, software for queries, reports and analysis tools makes up $72 \%$, but has increased by only $0.7 \%$ in 2015. The second segment, the market for advanced and predictive analytics tools grows by $7.8 \%$, and the last segment (market for content analytics tools) grows by $12.9 \%$. The year 2015 marks the beginning of the "big migration" towards cloud BI. In 2015, the onpremises part of BI market increased by only $1.2 \%$, while revenue from public cloud services went up by $38.5 \%$. This was the first year in which public cloud BI revenue makes up more than $5 \%$ of $\mathrm{BI}$ instruments and analysis market (9).

In 2015, SAP continues to be the largest BI software and analytical instruments producer with annual revenue amounting to more than $\$ 2$ billion. However, its share is shrinking due to the negative effects of exchange rates and fierce competition. SAP is followed by Microsoft, SAS, IBM and Oracle - each having sales of more than a $\$ 1$ billion on this market. The five biggest vendors have a combined market share of $52 \%$, which is falling down as compared to previous years (market share was 58\% in 2013 and 59\% in 2010). Nearly half of world sales are made by the so-called MISO group (Microsoft, IBM, SAP and Oracle) $(47.7 \%$ - 2013, 46.1\% - 2014, $42.3 \%$ - 2015, respectively). The decrease in the share of the biggest five producers and the MISO group is due to the increased popularity of visual discovery software and also the increasing share of new generation of BI offering strictly cloud-based solutions (9).

According to IDC analysts, for the period 2013-2015, the number of participants in world BIS market continued to grow. For example, the sales share of "Other" grow during those years $(27.4 \%$ - 2013, $28.1 \%$ - 2014, $29.7 \%$ 2015, respectively).

According to Gartner, modern BIS continue to develop faster than the market which makes up for the drop in sales of traditional BIS (8). Innovative BI and analysis platforms are increasingly successful in meeting customer requirements regardning ease of use, speed, and providing a deeper analytical insights based on data. The share of modern BI sales will continue to be greater than that of traditional BI, but its growth rate is slowing down from about 64\% in 2015 through 30\% in 2016 to $19 \%$ in 2020 (11).
KLISAROVA-BELCHEVA S., et al.

\section{BI market in Bulgaria}

A CBN agency research by Panoff, Stoychev $\&$ Co. on the development of BIS market in Bulgaria until 2013 shows that during that period, there were 44 companies offering BI software, and only 13 of them have managed to implement BI solutions. Implementers that offer Oracle or SAP BI software are the most numerous. The research notes that, currently, the market is too concentrated and predominantly large companies that advantage of that. The report indicates that out of 148 contracts from Operational programme "Development of the Competitiveness of the Bulgarian Economy" for purchasing business software, only one project involved implementation of BIS (12).

38 integrators have implemented BI software for customers in 16 vertical industries, and the projects in 3 of these industries account for $74 \%$ of the market. The main BI providers in Bulgaria are Balkan Services, distributor of Qlik (45 implementations), Team Vision distributor of Tableau and Microsoft with Power BI, SQL Server, etc. Unlike ERP and CRM software, BI systems are most commonly employed by large corporations. This fact clearly indicates that the potential for implementing BI software in this group as well as in SME is still quite high. The agency's forecast for 2017 and 2018 are that business customers' interest in implementing BI software is likely to grow and exceed the results from 2015 and 2016 (13).

\section{A model of modern BI architecture}

According to research by Dresner Advisory Services (DAS) (14-15), the following components are essential to the development of modern BIS:

- Big data analyses - They get researchers' attention as data in modern organizations are constantly growing in volume, have heterogeneous composition and needs to be updated frequently (16);

- Embedded analyses - According to Eckerson, we are witnessing two main alternatives in BI development over the last 35 years: reports aimed at users and analyses aimed at power users. In recent years, however, there is a convergence of the two alternatives toward embedded analyses and analytical functionality is embedded directly in business applications (17);

- IoT analyses - the capability of IoT to connect multiple devices, to gather and analyze raw data created by this devices as well as convert them to useful information, makes this technology a logical next step in building BIS. 
KLISAROVA-BELCHEVA S., et al.

The DAS research covers $33 \mathrm{BI}$ technologies and initiatives and three of them are included for the first time - natural language analytics, video analytics, and data catalog. The results of this research show that working with reports, visualization and self-service are vital to customers and video analyses, edge computing and IoT are presently immaterial (15). We check the validity of these conclusions by juxtaposing these data with those from a similar research, Importance of Business Intelligence Trends in 2017 $(\mathrm{n}=2,772)$, where 21 trends in BIS development are compared. In it, surveyed BI users consider the following to be the most important for BIS development: data discovery/visualization, self-service BI and data quality/master data management. The least significant are Hadoop, data labs/data science, cloud BI and data as a product/open (18). We notice a coincidence in two of the most preferred functionalities (visualization and self-service), which is proof for the reliability of the assessments from the two research papers.
Fundamental technologies - queries, reports, dashboards, are still strategically important for BIS development. The priority of top technologies has remained practically unchanged since 2013. There is increase in interest in data discovery, integration with operational processes, and data storytelling.

Gartner researchers believe that the main characteristic of modern BI is their functionality allowing business users to discovery patterns in the data visually.

Building on the Juniper Networks BI framework and in accordance with the conclusions made above, we propose a new architecture of a modern BIS (Figure 2). The purpose of the model's components is as follows: the first layer (Backend) contains internal and external BIS data sources company, Web, mobile, and sensors data. This model envisions integration of data into relational and/or non-relational databases, as well as their transformation into OLAP-cubes. Two types of processing are possible: offline and real time, whereas for shorter response times, technologies such as in-memory, cloud or edge computing are engaged.

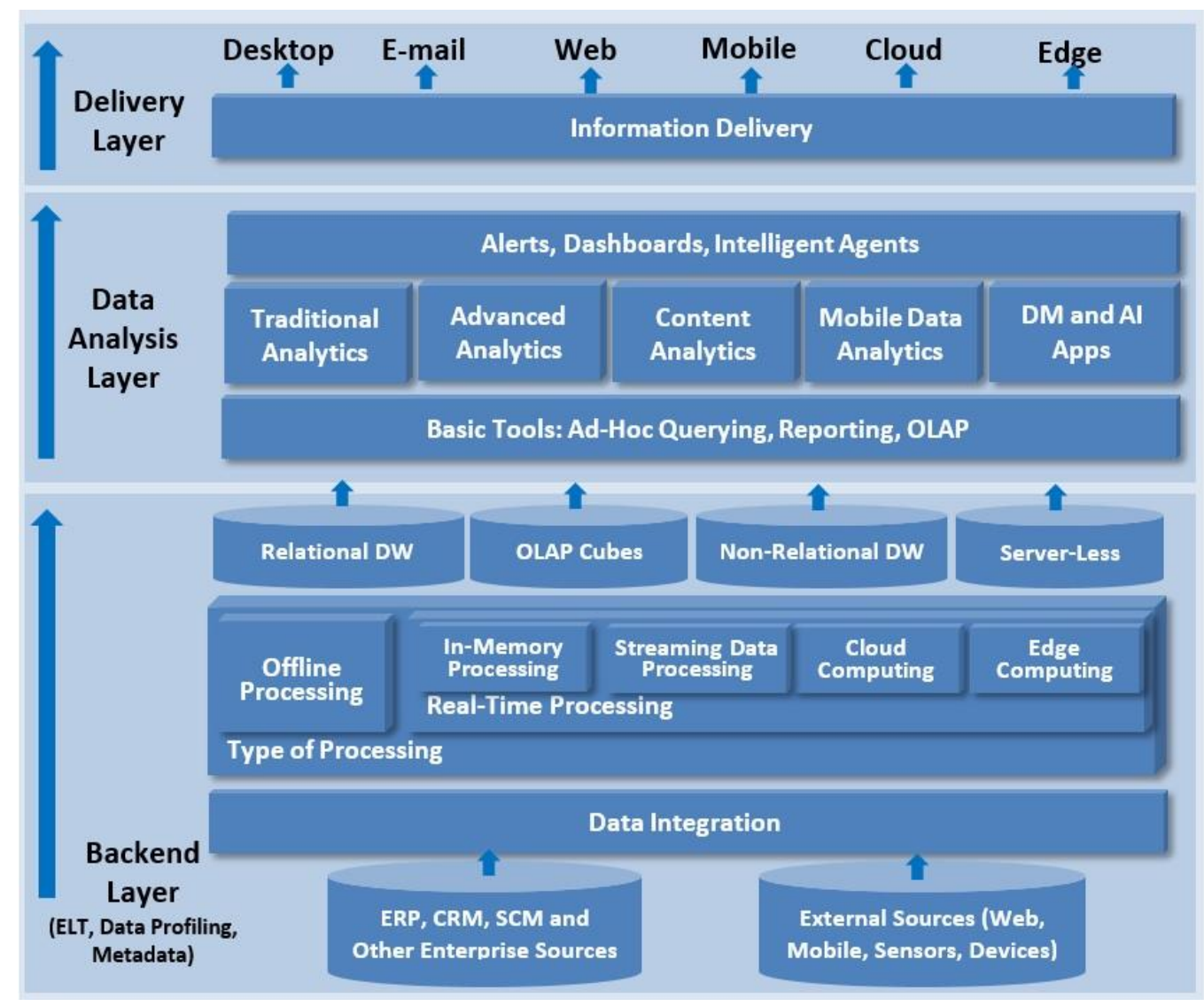

Figure 2. System Model of Modern BIS

The next layer, Data Analysis, consists of five groups of tools: for traditional analysis, advanced analysis, content analysis, mobile data analysis, and data mining and artificial intelligence. The traditional analysis group encompasses analysis based on a model predefined by the company's IT experts. The modern BI platforms enable business users to 
KLISAROVA-BELCHEVA S., et al.

explore data directly, without needing a predefined model. The advanced analytics group includes new technologies such as data discovery/visualization, data storytelling, spatial/location analysis, Big data, etc. Content analysis is concerned with analysis of text, video and graphical data, while special mobile data analytics methods are applied to mobile data. To data mining and artificial intelligence applications we assign modern statistical analysis tools, including predictive analysis, sentiment analysis, natural language analysis. And finally, the last, third layer, Delivery Layer, presents analysis results to end users directly in company applications (via embedded $\mathrm{BI}$ ) or via various communication channels (e-mail, Web, mobile, cloud, edge).

The main advantage of the new model in comparison with the one by Juniper Networks is that, instead of just revolving around the needs of an organization's managerial levels, here the model incorporates a significant part of the innovative IT technologies that have been proposed in the last five years. This change in structure is also due to the fact that modern BIS offer functionality that is useful to all managerial hierarchy levels. New BI technologies are at the base of all three building layers of the model - from the integration layer to the one presenting the final result.

\section{DISCUSSION}

There is a wide variety of BIS and numerous providers. Tableau, SAP, Qlik, Oracle and others are the companies whose products customers prefer most often. In a significant number of cases, providers of business software (ERP, CRM and others) offer BI solutions, nevertheless the market has many companies that produces BIS only. Traditional market players such as IBM, SAP, Oracle and MicroStrategy have reached the maturity phase of their BI products and generate stable revenue from their investments in models and analytical tools from previous years. Reduced product differentiation and price pressure proove the maturity of the market, which is saturated with BI providers.

Buyers prefer BI products with modern functionality such as self-service BI, working with a combination of sources of various data, etc. Gartner connects the future of BI with the functionality smart data discovery (naturallanguage processing, natural-language query and natural-language generation) for text- and voice-based interaction and its realization will hold a significant sway over the future ranking in the Quadrant.
In Bulgaria BIS implementations are relatively rare and only in large companies, however, new investments within the framework of the new "Operational Programme Innovations and Competitiveness 2014-2020" programme period are expected.

The proposed model covers base as well as innovative components of modern BIS: artificial intelligence, IoT, edge computing, content analysis (video, graphical, etc.). The advantage of the proposed BI architecture is that its three layers (backend, data analysis and delivery) reflect modern BI technologies. In addition to data warehouses and OLAP cubes, data are stored in non-relational warehouses or are processed in real-time (in-memory technology, edge computing, big data analytics). Modern analysis tools have their place in the new model: visual data discovery, data storytelling, video analysis, mobile data analysis, natural language analysis, as involvement from an IT team is no necessary (self-service BI, collaborative BI, etc.). End users' access to BI means is additionally alleviated via embedding BI in the company's business software - embedded BI.

The proposed new BI and analytics architecture supports fast and on time processing of data concerning manufacturing, products, customers and suppliers in all functional areas of an enterprise and increases operating excellence of organisations.

\section{CONCLUSION}

BI and analytical platforms market is highly competitive - the number of vendors is growing, the products and technologies that are offered have increasingly richer functionality, prices of traditional BI solutions are falling. Modern BI market is dynamic - new participants emerge and old ones disappear, market shares change as well as the growth rate of participants' sales. The number of customers and users significantly rose in 20132016. Business realizes the importance of BI software for improving competitiveness and invests more in it. The new BI system model can serve as a benchmark for comparison in researching future technological innovations in BI. It is flexible and can be adapted to reflect changes.

The choice of software product is heavily determined by the offered functionality, therefore, the next logical steps in future research are:

- analyzing functional characteristics of commonly used BI tools and 
- proposing a multi-criteria system for their evaluation.

Knowledge of current state of affairs, main participants and offered products on the BI market will aid potential clients in choosing suitable BI solution.

ACKNOWLEDGEMENTS This paper was sponsored as a part of project SR17 FESS 012 / 24.04.2017 at the Scientific Research Fund of the University of Plovdiv Paisii Hilendarski.

\section{REFERENCES}

1. Dresner, H., The Performance Management Revolution: Business Results Through Insight and Action. John Wiley \& Sons, Hoboken, NJ, pp 231, 2007.

2. Moss, L. T., Atre, S., Business Intelligence Roadmap: The Complete Project Lifecycle for Decision-Support Applications. Addison Wesley, Boston, MA, pp 576, 2007.

3. Popchev, I., Radeva, I., Decision support system for investment preference evaluation under conditions of incomplete information. Proc. 3rd Intern. Conf. Information Research, Applications and Education, 189-190, 2005.

4. Ilieva, G., Yankova, T., Klisarova, S., Cloud Business Intelligence: Contemporary Learning Opportunities in MIS training. Proc. Balkan Conf. on Informatics, 25-32, 2015.

5. Evelson, B., Nicolson, N., Topic Overview: Business Intelligence. Forrester, 2008.

6. Negash, S., Gray, P., Business Intelligence. In: Burstein F., Holsapple, C.W. (eds.), Handbook on Decision Support Systems 2. Part of the series International Handbooks Information System. Springer-Verlag, Berlin Heidelberg, pp 175-193, 2008.

7. Dresner Advisory Services, Wisdom of Crowds Business Intelligence Market Study. pp 94, 2012.

8. Sallam, R. L., Howson, C., Idoine, C. J., Oestreich, T. W., Richardson, J. R., Tapadinhas, J., Magic Quadrant for

\section{KLISAROVA-BELCHEVA S., et al.}

Business Intelligence and Analytics Platforms. pp 126, Gartner, 2017.

9. Vesset, D., Gopal, C., Schubmehl, D., Bond, C., Olofson, C. W., Worldwide Business Analytics Software Market Shares, 2015: Healthy Demand Despite Currency Exchange Rate Headwinds. IDC, pp 12, 2016.

10.Capterra, Top Business Intelligence Software Products. http://www.capterra.com/business-

intelligence-software/, 2017. Last visited on 30.06.2017

11.Gartner, Gartner Says Worldwide Business Intelligence and Analytics Market to Reach $\$ 18.3$ Billion in 2017, http://www.gartner.com/newsroom/id/3612 617 Last visited on 30.06.2017

12.Computerworld, CBN: BI software has been implemented in 30 vertical industries so far.

http://computerworld.bg/43847_cbn_bi_sof tuer_e_vnedren_v_30_industrialni_vertikali _dosega Last visited on 30.06.2017

13.CBN, The BI Software Market in Bulgaria: 16 Years and Hundreds of Companies Mastering Business Analysis. http://blog.cbn-bulgaria.com/2017/02/bi16.html - in Bulgarian Last visited on 30.06.2017

14.Dresner Advisory Services, Wisdom of Crowds Business Intelligence Market Study. pp 144, 2015.

15.Dresner Advisory Services, Wisdom of Crowds Business Intelligence Market Study. pp 167, 2017.

16.Ilieva, G., Yankova, T., Klisarova, S., Big Data Based System Model of Electronic Commerce. Trakia Journal of Sciences, 13(1):407-413, 2015.

17.Eckerson, W., Embedded Analytics: The Future of Business Intelligence. Eckerson Group, pp 18, 2016.

18.Business Application Research Center, Importance of Business Intelligence Trends in $2017 \quad(n=2,772) . \quad \mathrm{https}: / / \mathrm{bi}-$ survey.com/top-business-intelligencetrends-2017 Last visited on 30.06.2017 